\title{
Facilitative effects of punishment on aggressive behavior in the Siamese fighting fish'
}

\author{
KENNETH B. MELVIN and JOHN E. ANSON, University of \\ Alabama, University, Ala. 35486
}

Male Siamese fighting fish (Betta splendens) were reinforced for swimming through an aperture by a mirror presentation which released an innate aggressive display. Moderately intense shock-punishment of the operant response increased the vigor of the display and, temporarily, the rates of the operant response. Gradual decreases in rate within and across nonpunished sessions reflected short-term and long-term habituation to the mirror image.

Recently there has been a justifiable resurgence of interest in the nature of aggressive behavior. Little is known, however, about the effects of punishment on aggression. One type of interspecific aggression, mouse-killing by rats, was suppressed by punishment (e.g., Myer \& Baenninger, 1966).

An appropriate organism for basic research on aggression is the male Siamese fighting fish (Betta splendens). The sight of another male Betta releases a species-specific aggressive display, followed by a prolonged and sometimes fatal fight. Display components include gill-cover extension, fin erection, undulating movements, color changes, and frontal approach. Furthermore, Thompson (1963) found that the visual image of a male Betta (and the ensuing display) was a positive reinforcer for an operant response-a finding confirmed by others (e.g., Hogan, 1967).

While Adler \& Hogan (1963) reported that punishment of gill-cover extension may suppress the display, further research is indicated. For example, aversive events often elicit aggression in a variety of species (e.g., Ulrich, 1966). Also, the effects of punishment are often determined in a complex fashion; one salient variable is the location of punishment in the response sequence (Church, 1963).

The present study investigated the effects of punishment on an operant response of fighting fish. This response can be considered as aggressive behavior, since it produced a mirror image and, consequently, the aggressive display. Learning and habituation of this operant aggressive response were also studied.

\section{SUBJECTS AND APPARATUS}

Eight naive male Siamese fighting fish served as Ss. They were red in color, $1 \frac{3 / 4}{4}-2 \frac{1}{4}$ in. long, and were fed daily on Tetra-Min throughout the experiment.

The apparatus consisted of two independently automated 2-gal aquaria. A black Plexiglas bar, 93/4 $\times 3 / 4 \times 13 / 4$ in., with a centrally positioned aperture, was located $2 \mathrm{in}$. above the floor of the tank. The bar was centered between the long sides of the tank. A light beam traversed the center of the bar (and thus the aperture) and hit a photocell at one side of the tank. Electric shock was delivered through two stainless steel screens attached to the short (6-in.) sides of the aquarium. Water temperature was maintained at $80 \mathrm{deg} \mathrm{F} \mp 1 \mathrm{deg}$.

Mirror presentation was accomplished by turning off two 40-W bulbs located 11 in. behind a two-way $5 \times 7$ in. mirror attached to a long side of the tank. The other three sides of the tank were enclosed. A miniature $28-\mathrm{V}$ house light was turned on during the offset of the $40-\mathrm{W}$ bulbs. A response was recorded as the fish came out of the aperture. No further responses were counted or reinforced during reinforcement duration. During adaptation and between sessions, a red filter was placed in front of the $40-\mathrm{W}$ bulbs and a cover was lowered over both sides of the aperture.

\section{PROCEDURE}

After $24 \mathrm{~h}$ of adaptation, Ss were given two 24-h operant-level sessions, in which responses were counted but not reinforced. The fish then received a $24-\mathrm{h}$ training session during which responses produced the mirror for $20 \mathrm{sec}$. Following this session, the aperture cover was lowered and the red filter replaced for $22 \mathrm{~h}$.

The next 14 daily sessions were $2 \mathrm{~h}$ in duration and $22 \mathrm{~h}$ apart. As in training, Ss were given a continuous schedule of reinforcement (CRF). After five CRF sessions, shockpunishment was administered for three sessions. A .50-sec, 60-cycle ac shock immediately followed the operant response, as did the mirror reinforcement. Shock intensity was gradually raised over the CRF/punishment sessions: It was $5 \mathrm{~V}$ for the first punishment session (Day 6), 5 and $7 \mathrm{~V}$ on Day 7 , and 7 and $9 \mathrm{~V}$ on Day $8 . .^{2}$ Within-day voltage changes on Days 7 and 8 were made after the first hour. Three nonpunished CRF sessions followed on Days 9-11. On the next two days punishment was reintroduced, with 7 and $9 \mathrm{~V}$ used on Day 12 and 9 and $10 \mathrm{~V}$ on Day 13. During a final session, a very strong shock-punishment $(11-15 \mathrm{~V} \mathrm{ac})$ was administered to determine whether suppression could be obtained.

\section{RESULTS}

Figure 1 shows the mean response rate over the first $5 \mathrm{~h}$ of training (operant level of responding ranged from 1.5-4.6 responses $/ h$ ). Clearly, the fish learned the response, reaching asymptote after $4 \mathrm{~h}$. This increase in rate was highly significant $(F=14.01, \mathrm{df}=14 / 98, \mathrm{p}<.001)$. During the next $17 \mathrm{~h}$, however, mean response rate gradually decreased to 6.3 responses $/ 20 \mathrm{~min}$ in the last $1-\mathrm{h}$ interval. A test of this declining trend over Hours 5-24 was significant $(\mathrm{F}=2.11$, $\mathrm{df}=6 / 19, \mathrm{p}<.01)^{3}$

The overall trend shown in Fig. 2 is downwards; although analysis of variance of Sessions 1-5 was not significant, a test of the extremes, Session 1 vs 5 mean rates, reached significance $(t=2.78, p<.05)$. This gradual decrease was reversed with punishment, i.e., all Ss increased rate of response from Sessions 5 to 6 , a highly significant effect $(t=5.92$, $\mathrm{p}<.001)$. One could also consider Sessions $1-5$ as the base

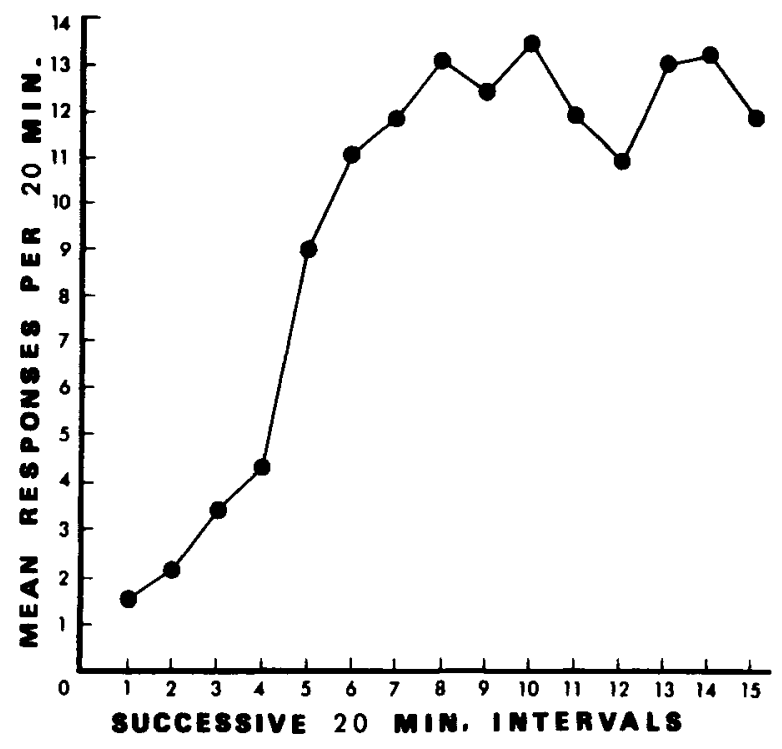

Fig. 1. Acquisition performance over $5 \mathrm{~h}$. 


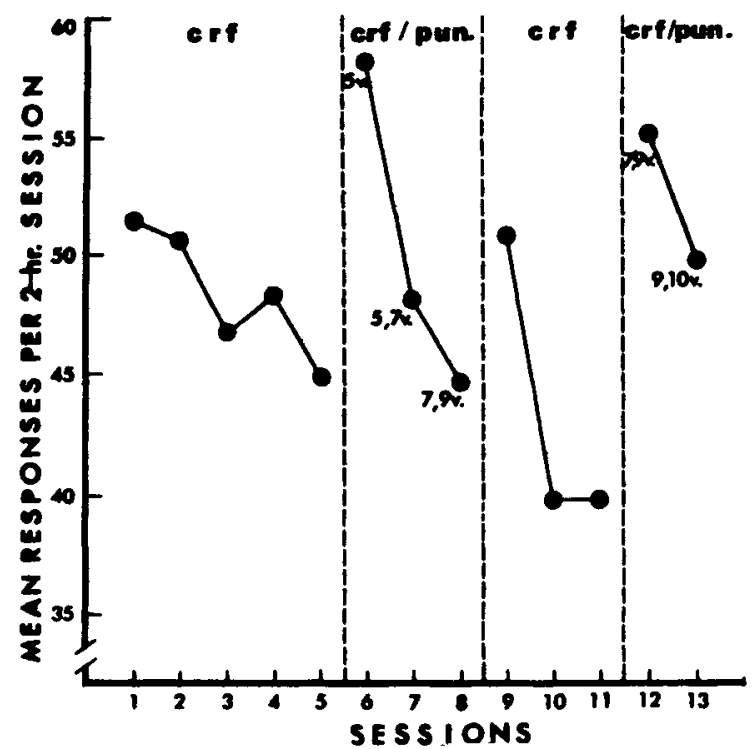

Fis. 2. Mean rate of reoponding over 13 daily 2 h rexions. Punishment (CRF/PUN) was administered during Sescion 6-8 and 12-13.

line, although this comparison may be too conservative due to the declining trend. Even so, mean rate for Session 6 was also significantly higher than the mean of median rates for Sessions $1-5(t=4.12, p<.01)$. The next two punishment sessions ( 7 and 8 ) were not significantly different from Session 5.

Figure 2 also indicates a possible "recovery" effect from Sessions 8 to 9; however, it was not significant. Reintroduction of punishment on Sessions 12 and 13 again increased mean rate. This effect was not statistically significant, primarily due to two "contrary" fish which showed suppression while six other Ss increased their response rates. On Session 14, the voltage was raised from 11 to $15 \mathrm{~V}$, resulting in suppression for all fish. The Session-14 mean rate $(4.5 / h)$ was close to operant level. Behavioral effects of the 15-V shock included a twitch strong enough to flip the fish to the surface.

Observation revealed that moderate shock led to a more intense display. While the two Es agreed that punished fish displayed longer and more vigorously, more systematic investigation is warranted.

\section{DISCUSSION}

Figure 1 represents the learning curve for fighting fish reinforced by the mirror image/display. While other Es had presented rate changes over time, any representation of the learning process was obscured by the averaging of response rate over 24h sessions (e.g., Thompson, 1963). The curve shown in Fig. 1 is not unlike many found with more conventional types of reinforcement (Kimble, 1961).

While the response typically reached asymptote after $4 \mathrm{~h}$, continued training revealed short-term habituation. Long-term habituation also occurred, i.e., a rate decrement over sessions even with 22-h intersession intervals. Both short- and long-term habituation of the display were previously demonstrated (Baenninger, 1966; Clayton \& Hindle, 1968). We feel that the decrement in operant rate reflects habituation of the display.

Moderate intensities of punishment did not suppress behavior; in fact, temporary facilitation was shown. This increase in response rate reflected an intensification of the aggressive display through punishment. While Adler \& Hogan (1963) reported suppression of gill-cover extension with punishment, there are certain crucial differences between our study and theirs; they used intense punishment, punished the display, and terminated the sight of the mirror image (or another fish) immediately after punishment. Certainly, intensity of punishment is an important variable. Our finding of suppression during the last session is compatible with the results of Adler and Hogan, and can be attributed to the high level of shock intensity.

The mechanism by which facilitation occurred is not immediately evident. The pain of the shock might have raised the level of emotionality, perhaps by stimulating the sympathetic division of the autonomic nervous system. Also, the literature on pain-elicited aggression seems relevant (e.g., Ulrich, 1966). Although Bettas do not require pain to initiate aggressive behavior, as did the Ss used by Ulrich and his associates, pain appears to strengthen the display.

While punishment typically suppresses behavior, under certain conditions it results in facilitation, e.g., punishment of an ongoing aversively-motivated locomotor response (e.g., Brown, in press; Melvin \& Martin, 1966). There are certain commonalities between this self-punitive "vicious-circle" phenomenon and the present paradigm. First, shockpunishment elicits a response which is not incompatible with the original response (i.e., nunning or swimming forward). Secondly, punishment is followed by reinforcement. Finally, shock-punishment increases the level of arousal. However, the two paradigms are also quite different in certain ways, e.g., one involves an innate aggressive response, the other a learned escape response. Still, one or more of their shared qualities may be a crucial determinant of punishment-induced facilitation.

It should be noted that, in the present experiment, the Bettas were engaging in a great deal of self-punitive behavior. In fact, through Session 13 they typically approached, and endured, over 250 shock-punishments. In terms of resistance to punishment, the mirror image/display seems to be a powerful reinforcer. Paradoxically, it is a relatively weak reinforcer in terms of resistance to extinction (e.g., Hogan, 1968). We agree with Hogan that display and food represent two different kinds of reinforcers which depend on different mechanisms for their effects: In fact, responses reinforced by display may have more in common with aversively-motivated behavior than with food-rewarded responses.

\section{REFERENCES}

ADLER, N., HOGAN, J. A. Classical conditioning and punishment of an instinctive response in Betta splendens. Animal Behaviour, 1963, $11,351-354$

BAENNINGER, R. Waning of aggressive motivation in Betta splendens. Psychonomic Science, 1966, 4, 241-242.

BROWN, J. S. Factors influencing self-punitive locomotor behavior. In B. A. Campbell and R. M. Church (Eds.), Punishment. New York: Appleton-Century-Crofts. In press.

CHURCH, R. M. The varied effects of punishment on behavior. Psychological Review, 1963, 70, 369-402.

CLAYTON, F. L., \& HINDE, R. A. The habituation and recovery of aggressive display in Betta splendens. Behaviour, 1968, 30, 97-105.

HOGAN, J. A. Fighting and reinforcement in the Sismese Fighting Fish (Betta splendens). Journal of Comparative \& Physiological Psychology, 1967, 64, 356-359.

KIMBLE, G. A. Hilgard and Marquis' Conditioning and learning. New York: Appleton-Century-Crofts, 1961.

MELVIN, K. B., \& MARTIN, R. C. Facilitative effects of two modes of punishment on resistance to extinction. Journal of Comparative a Physiological Psychology, 1966, 62, 491494.

THOMPSON, T. Visual reinforcement in Siamese Fighting Fish. Science, $1963,141,55-57$.

ULRICH, R. Pain as a cause of aggression. American Zoologist, 1966, 6, 643-662.

\section{NOTES}

1. This research was supported by Grant MH 15768-01 from the National Institute of Mental Health.

2. A pilot study indicated that Ss habituated to constant shock levels; therefore, we gradually increased shock intensity until the final session. The typical reaction to shock was a marked twitch, followed by darting forward. Two Ss reacted more strongly than the others to shocks of $9 \mathrm{~V}$ and above.

3. One $S$ did not learn the response until the 20 th $\mathrm{h}$; its data were excluded from this analysis. 